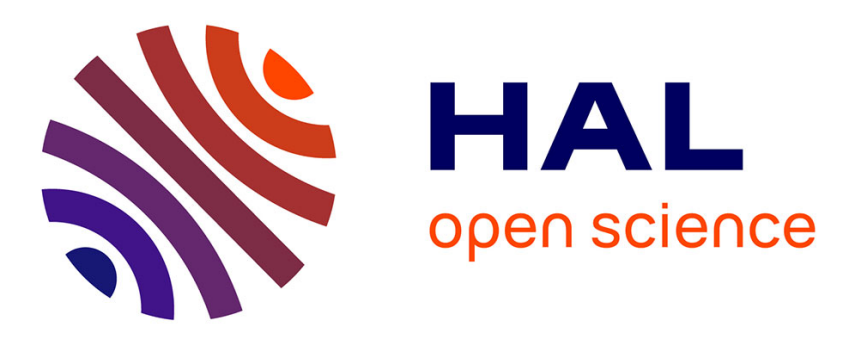

\title{
CTI and Multimedia applications applied to intelligent networks
}

\author{
Xavier Scharff, Pascal Lorenz, Zoubir Mammeri
}

\section{To cite this version:}

Xavier Scharff, Pascal Lorenz, Zoubir Mammeri. CTI and Multimedia applications applied to intelligent networks. 7th IEEE Intelligent Network Workshop and 5th International Conference on Intelligence in Networks - IN'98, 1998, Bordeaux/France, 10 p. inria-00098734

\section{HAL Id: inria-00098734 \\ https://hal.inria.fr/inria-00098734}

Submitted on 26 Sep 2006

HAL is a multi-disciplinary open access archive for the deposit and dissemination of scientific research documents, whether they are published or not. The documents may come from teaching and research institutions in France or abroad, or from public or private research centers.
L'archive ouverte pluridisciplinaire HAL, est destinée au dépôt et à la diffusion de documents scientifiques de niveau recherche, publiés ou non, émanant des établissements d'enseignement et de recherche français ou étrangers, des laboratoires publics ou privés. 


\title{
CTI AND MULTIMEDIA APPLICATIONS APPLIED TO INTELLIGENT NETWORKS
}

X. Scharff*+ \# , P. Lorenz* and Z. Mammeri\#

- * University of Haute Alsace, Colmar - France

- Alsatel, Eckbolsheim - France

- \# Loria, Nancy - France

CTI AND MULTIMEDIA APPLICATIONS APPLIED TO INTELLIGENT NETWORKS

\author{
X. Scharff*+\#, P. Lorenz* and Z. Mammeri ${ }^{\#}$ \\ * University of Haute Alsace - IUT/GTR \\ 34 rue du Grillenbreit - 68008 Colmar - France \\ Phone: 33 (0)389202366 - Fax: 33 (0)389202359 \\ Email: lorenz@colmar.uha.fr \\ \# Loria - 2 avenue de la Forêt de Haye, \\ 54516 Vandoeuvre les Nancy cedex - France \\ Email:mammeri@loria.fr
}

+ Alsatel - 11, rue jean-Monnet - 67201 Eckbolsheim - France Phone: 33 (0)388789746 - Fax: 33 (0)388789740

Email: scharff@colmar.uha.fr 
- Multimedia constraints appear in CTI (Computer Telephony Integration) environments

- APIs (Application Program Interfaces) allow implementation of CTI functions (TAPI, TSAPI, ...)

- New technologies such as ATM networks are used for CTI and multimedia applications

\section{Introduction}

Today there is a lot of multimedia applications which imply different constraints such as data transfer and data management constraints. In intelligent networks, a multimedia application uses different types of data (such as audio and video flows) which must be synchronized [YEN 94], [FLA 94], [MES 96]. CTI applications are often distributed and use many servers or telecommunication servers to transfer, manage and store databases with pictures, sounds, texts and videos. The synchronization of computer and telephony functions, called CTI (Computer Telephony Integration), manages telephone with computers [GRE 96], [SCH 97]. Therefore multimedia constraints appear in CTI environments.

Today CTI applications have computers, multimedia and telephone constraints. CTI and multimedia applications use the same source of information (voice, data, video) and must be able to access to distributed data in a network environment. 
- Multimedia = Text and/or Sound and/or Video and/or Picture and/or File

- CTI and multimedia applications use the same source of information (voice, data, video, ...)

- To have good QoS (Quality of Service), it is important to introduce the notions of :

- available bandwidth,

- allowed jitter,

- synchronization and priority between the applications.

\section{Multimedia applications}

A media represents how the information are represented, sent or stocked. A media is an information which can be a text, a sound, a video, a picture or a file [PRO 94], [RIJ 95], [SCH 92].

Multimedia applications (such as visioconference) integrate data coming from different sources such as fixed or moving pictures, sounds, texts, files, etc... Multimedia can be seen as the alliance of television (for the moving capability) and computer science (for the computing capability).

Multimedia comes from the merge of television, computer, telephone and integrates, at the same time, data coming from different media. Thus, a multimedia application can be represented as follows:

\section{Multimedia $=$ Text and/or Sound and/or Video and/or Picture and/or File}

Today powerful tools allow to create multimedia applications. Moving pictures use a lot of computer resources and then temporal constraints appear. More and more, the different data used by multimedia applications must be synchronized (for example, the visioconference implies the synchronization of audio and video).

It is important to introduce the notions of :

- available bandwidth,

- allowed jitter,

- synchronization and priority between the applications, that are important to provide the required QoS (Quality of Service). 
- APIs of CTI applications support a broad range of multimedia applications

- Independence of the APIs from the connection and the protocol

- Open APIs do not take into account network layers or manufacturing constraints

- Windows Telephony API (TAPI) focuses on the desktop, generally a single PC and a Telephone

APIs (Application Programming Interface) of CTI applications support a broad range of multimedia applications which allow the management of telephone from the simpler dialer or data communication applications to complex call centers management with access to telephony features.

Some CTI architectures are focused on call centers (automatic call distribution, predictive dialing, ...) or on Integrated Services Digital Network (ISDN) calls from personal computers. Widespread success of CTI requires a broad range of commercial applications.

Many companies use proprietary APIs, then final users must buy hardware (PBX, cards, ...) and software at the same manufacturer. However open APIs implement drivers working with any network topology.

Open APIs do not take into account network layers or manufacturing constraints and they are not restricted to a given network environment. They allow to connect a wide range of equipment, offer a lot of capabilities (such as PBX, ISDN, cellular, etc) and flexibility to integrate telephone and computers.

Successful APIs encompass the features of different connections models, allowing user's application telephone calls regardless of where and or how their computers are connected to the network.

Windows Telephony API (TAPI) focuses on the desktop, generally a single PC and a telephone. The desktop is assumed to be one end-point of each call, thereby simplifying the API and making it easier to use. 


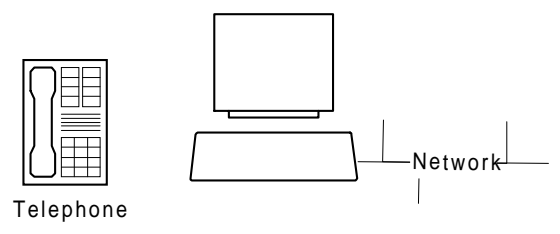

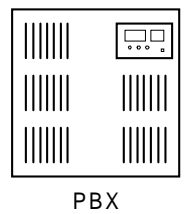


ERROR: undefined

OFFENDING COMMAND: 1. !

STACK:

1.0 